MEMÓRIA

\title{
Escola Politécnica de São Paulo: engenharias políticas no ensino superior paulista nos inícios republicanos
}

Josianne Francia Cerasoli*

\section{RESUMO}

A Escola Politécnica, origem da instituição que desde 1934 integra a Universidade de São Paulo, foi organizada pelo governo paulista e instaurada em 1893. Este estudo analisa os significados associados a essa instituição que se articula ao prestígio desfrutado pelas ciências matemáticas no século XIX. Identificam-se, na fundação da Escola e nas ações dos engenheiros no período, as aproximações entre os projetos políticos liberais e os saberes e práticas da engenharia, tidos como científicos e de perfil predominantemente pragmático. Considerando o projeto da Politécnica e seus meios de difusão de conhecimentos - anuários e periódicos - discutem-se os efeitos imaginados a partir da criação da Politécnica, também pelo sensível potencial de inovação e atualidade a ela associados.

PalaVRas-Chave | Ensino Superior; Instituições de Pesquisa; Políticas Governamentais; Escola Politécnica de São Paulo

Códigos JEL: I23; 128; O25

Departamento de História, Instituto de Filosofia e Ciências Humanas da Universidade Estadual de Campinas (Unicamp), Centro Interdisciplinar de Estudos sobre a Cicade (Ciec) da Unicamp. E-mail: cerasoli@g.unicamp.br 


\section{ABSTRACT}

The Polytechnic School, beginning of the institution merged into University of S. Paulo since 1934, was organized by the regional government of the State of S. Paulo in 1893. This study analyzes the meanings associated with this institution articulated to the prestige enjoyed by the mathematical sciences in the nineteenth century. It identifies in the foundation of the School and in the actions of the engineers the approximations between the liberal-political projects and the knowledge and practices of the engineering, perceived as scientific and of predominantly pragmatic profile. Considering the Polytechnic project and its means of knowledge diffusion - annals and periodicals - the imagined effects of the Polytechnic creation are discussed, also due to the sensitive potential of innovation and the currentness relevance associated with it.

KeYwords | Higher Education; Research Institutions; Government Policy; Polytechnic School of S.Paulo

JEL CODES | I23; 128; O25 


\section{Introdução}

Projetos que mobilizam a área de educação têm assumido contemporaneamente papel decisivo na definição de políticas públicas que traduzem projetos para o país. Mesmo um olhar panorâmico atento a notícias recentes e pautas governamentais nos últimos anos reuniria indícios contundentes para se confirmar a importância estratégica desses projetos. E não seria possível caracterizá-los como próprios a algum plano específico ou mesmo a uma ou outra forma de governo, tampouco seria suficiente situá-los como iniciativas voltadas para uma concepção específica de inovação, dadas as características processuais que assumem em meio às sucessivas mudanças que os envolvem. Porém, pode-se afirmar que, sob concepções de Estado e sociedade de matriz republicana e liberal, os projetos educacionais têm se constituído como elementos inovadores estratégicos, entremeando-se muitas vezes a iniciativas dos governos de modo inseparável.

No início da Primeira República no Brasil, foi expressivo o impulso conferido ao ensino superior, sobretudo aquele voltado para áreas do conhecimento então consideradas decisivas para a imediata organização social e econômica do país, como a engenharia e a medicina. Figurava-se como pauta importante, ao lado do incentivo às escolas das chamadas "primeiras letras" e às instituiçôes para formação de docentes para tais escolas, essenciais ao projeto de cidadania republicano.

Foi precisamente para as áreas de medicina e engenharia que se voltaram a atenção e os recursos do Tesouro estadual paulista na última década do século XIX. Propostos quase simultaneamente, os projetos para as duas instituiçôes de ensino foram acolhidos pelos legisladores paulistas em 1891, logo após promulgada a primeira Constituição republicana no estado de São Paulo. Se a escola de medicina esbarrou inicialmente em dificuldades logísticas, sendo viabilizada apenas mais de uma década mais tarde, a de engenharia foi criada prontamente, após um período de debates relativamente curto na Assembleia Legislativa do estado, então bicameral, com Câmara dos Deputados e no Senado.

A Escola Politécnica, origem da instituição que desde 1934 integra a Universidade de São Paulo, foi autorizada pelo governo paulista a partir de dois projetos votados no Legislativo estadual em 1892: o primeiro criando duas escolas superiores, uma de agricultura e outra de engenharia; e o segundo estabelecendo o Instituto Politécnico. Uma modificação dessas duas leis, capaz de conciliar de algum modo os propósitos 
nelas inscritos, viabilizou a criação da Escola Politécnica de São Paulo, enfim autorizada pelo Legislativo em agosto de 1893 e prontamente inaugurada em fevereiro de $1894 .{ }^{1}$

\section{Atualidade e dimensões práticas como planos convergentes}

Ainda que algumas instituições para formação de engenheiros já funcionassem regularmente, como a Escola de Minas de Ouro Preto (desde 1876), a Escola Politécnica do Rio de Janeiro (desde 1874, organizada a partir da Escola Central, de 1858, oriunda da Escola Militar, de 1810), além das escolas de medicina e cirurgia da Bahia e da capital federal (ambas de 1808), a Escola Politécnica de São Paulo em 1894 foi a primeira a se constituir de modo inteiramente integrado aos projetos republicanos, precisamente no momento de consolidação da nova forma de governo. Foi financiada pelo governo paulista e organizada pelo seu primeiro diretor, Antonio Francisco de Paula Souza (1843-1917), que atuou como engenheiro em diversas obras públicas no estado, sobretudo de infraestrutura ferroviária, além de ocupar cargos administrativos, como a inspetoria e depois a Secretaria de Obras Públicas de São Paulo. ${ }^{2}$ O projeto de fundo liberal da Escola foi rapidamente convertido em uma das importantes bandeiras em prol do governo republicano, inclusive por seu incentivo ao desenvolvimento da produção agrícola e industrial, ao mesmo tempo que constituiu alavanca para a consolidação de modelos de ensino e pesquisa nos quais a preocupação com a inovação, em diferentes sentidos, recebe amplo estímulo.

A partir de então, foi desenvolvida uma série de iniciativas e projetos, voltados frequentemente para uma conciliação entre expectativas expressas em planos que poderíamos entender como político-econômicos e diretrizes pensadas para promover o desenvolvimento das áreas do conhecimento tidas como cruciais para tais planos. Aquilo que poderia ser visto como inovação, considerando os sentidos a ela atribuídos desde então, parece estar presente em numerosas ações gestadas na Escola Politécnica, por constituir, em certa medida, a própria razão de ser da instituição.

1 A Escola de Medicina foi proposta na Câmara dos Deputados de São Paulo no dia 13 de agosto de 1891 (Lei estadual n. 19 de 24/11/1891, criando a Academia de Medicina, Farmácia e Cirurgia), mas somente foi regulamentada em 1912 e efetivamente instalada em 1913. As três leis que originaram a Escola Politécnica foram: Lei n. 26, de 26/05/1892, autoriza o governo a fundar uma escola prática denominada Escola de Engenharia; Lei estadual n. 64, de 17/08/1892, autoriza a criaçāo de uma escola superior de ciências aplicadas às artes e indústrias, a ser denominada Instituto Politécnico; por fim modificadas em 1893 para execução de ambas e resolução das sobreposiçōes e conflitos entre os projetos, com a aprovação da Lei n. 191, de 24/08/1893, que estabelece o primeiro regulamento da assim chamada Escola Politécnica de São Paulo, com os cursos de Engenharia Civil, Engenharia Industrial, Engenharia Agrícola e curso anexo de Artes Mecânicas (SÃO PAULO, 1891, 1892, 1893, 1912).

2 Análises sobre a inserção de Paula Souza no meio profissional na época podem ser acompanhadas nos estudos de Campos (2010) e Cerasoli (1998). 
A organização de diversos laboratórios de experimentação, demonstração e desenvolvimento de pesquisas e estudos definiu desde o início um importante perfil da Politécnica, assinalando um lócus distintivo para os profissionais nela atuantes e dela egressos, sobretudo nas primeiras décadas de sua trajetória. Característica reiterada em numerosos documentos da instituição, talvez se possa identificar na busca por explicitar uma interdependência entre teoria e prática como distinção da Politécnica e como característica potencialmente inovadora. ${ }^{3}$ Entre vários exemplos desse potencial inovador, caberia destacar a instalação, desde os primeiros anos da Escola, de laboratórios, gabinetes e oficinas equipados para a realização de experimentos associados a cada uma das cadeiras previstas nos currículos dos cursos, a saber:

- Gabinete de Física Experimental

- Gabinete de Astronomia e Geodésia

- Gabinete de Topografia

- Gabinetes de Química Mineral e Orgânica

- Gabinete de Eletrotécnica e Física Industrial

- Gabinete de Resistência de Materiais

- Gabinete de Química Analítica e Industrial

- Gabinete de Botânica

- Gabinete de Veterinária e Zootecnia

- Oficinas (carpintaria, fundição, mecânica)

- Horto de Culturas e campo de Silvicultura ${ }^{4}$

São os primeiros laboratórios de engenharia construídos no país: resistência de materiais, máquinas, eletrotécnica e hidráulica. Entre os laboratórios, destacou-se na formação da Escola aquele vinculado diretamente ao curso de engenharia civil, destinado à realização e ensaios com materiais, o Gabinete de Resistência de Materiais. Instalado em 1899, tal laboratório estimulou pelo menos três ações que encontraram significativa repercussão ao longo das primeiras décadas de atividade,

3 É interessante observar, já em seu primeiro regulamento, o intuito de valorizar a formação direcionada à prática, em detrimento de alguma concepção mais especulativa. Os regulamentos seguintes assumiram progressivamente essa característica de modo mais explícito, uma vez que na instalação da Escola, segundo a legislação vigente, era necessário apresentar um regulamento alinhado ao praticado na Politécnica da capital federal para se obter autorização de emissão e diplomas. Essa discussão é aprofundada em Cerasoli (1998).

4 Uma série de documentos relativos às décadas iniciais da Politécnica foi digitalizada no projeto Memória, disponibilizado em 2015 no Portal Memória da Poli. Disponível em: <www.memoria.poli.usp.br>. Acesso em: 2 jun. 2017. Os laboratórios listados são referenciados no anexo 1 do Relatório 1908 ("Material escolar adquirido em 1908”), exceto o de Astronomia e Geodésia, para o qual se reclama ao longo do relatório a necessidade de um espaço adequado para seu perfeito funcionamento, apontando-se como localização ideal a avenida Paulista. De modo similar, reivindica-se também maior espaço para o Gabinete de Resistência de Materiais (ESCOLA POLITÉCNICA DE SÃO PAULO, 1908). 
todas entendidas, cada uma a seu tempo, como expressão de atualidade e inovação na engenharia não apenas no país. Primeiramente, ocorreu a publicação do Manual de Resistência de Materiais, em 1905 (Figura 1), organizado pelo Grêmio Politécnico, composto por estudantes dos cursos de engenharia, com base nos trabalhos no então Gabinete de Resistência de Materiais. ${ }^{5}$ A segunda ação foi a própria conversão do Gabinete em Instituto de Pesquisas Tecnológicas (IPT), em 1934, com apoio financeiro de empresas de transportes ferroviário, um ano após a instauração pelo governo federal do Instituto Nacional de Tecnologia. Ambos foram responsáveis, em parceria também com a Associação Brasileira de Cimento Portland, criada em 1936, pela terceira ação de expressiva repercussão: as discussões, entre 1937 e 1940, que originaram a Associação Brasileira de Normas Técnicas (ABNT), responsável pela sincronização dos parâmetros de construção, produção e serviços com os gabaritos globais (ABNT, 2011, 45-50).

A aplicabilidade dos conhecimentos provenientes da investigação científica pode ser assinalada como base para esse conjunto de iniciativas, em distintos contextos. Também se apresenta como fundamento para a definição do campo de atuação da Escola, seus docentes e seus egressos, e aparentemente orientou posturas decisivas na instituição. Desde os debates na esfera do Legislativo paulista sobre a pertinência de uma instituição superior de engenharia, fortalece-se paulatinamente essa concepção de teoria e prática entrelaçada a interesses - no sentido analisado por Stengers (1990), ao entender que todo conhecimento científico necessita suscitar interesse para adquirir significado socialmente e estabelecer seu campo de ação.

Considerando-se esse entendimento e essa inserção da Politécnica nas suas primeiras décadas, são analisados a seguir os termos em que essa concepção de conhecimento foi colocado em pauta, nos debates para aprovação da instituição na discussão final na Câmara dos Deputados estadual paulista. Em seguida apresenta-se uma seleção de documentos provenientes das publicações da Politécnica - seus extensos anuários e seu principal periódico -, entendidos como espaços cruciais para exercício e validação social das propostas de inovação provenientes do trabalho na Escola, à semelhança do Manual de Resistência de Materiais.

5 Usualmente citado como um estudo inovador, o Manual foi publicado pelo Grêmio e circulou inicialmente em São Paulo e no Rio de Janeiro, com repercussão imediata na imprensa. Săo citados os comentários de Adolpho del Vecchio no Jornal do Commercio, os artigos publicados no Correio Paulistano, no O Estado de São Paulo e na Folha Nova, bem como a manifestação crítica de Osório de Almeida no Club de Engenharia do Rio de Janeiro (PUJOL JR., 1905). O Grêmio Politécnico foi fundado em 1903 pelos alunos da Escola, tendo como primeiro presidente Alexandre Albuquerque, posteriormente, em 1917, o primeiro egresso a tornar-se lente da Politécnica. Sobre o IPT, é possível acompanhar mais detidamente os trabalhos desenvolvidos em torno do projeto "História Social do Trabalho e da Tecnologia como Fundamentos Sociais da Arquitetura e do Urbanismo", sediado n no LabFAU (Laboratório de Fundamentos Sociais da Arquitetura e do Urbanismo) da FAU-USP; entre eles, destacam-se os estudos de Gitahy (2001) e Gitahy e Pereira (2002). 


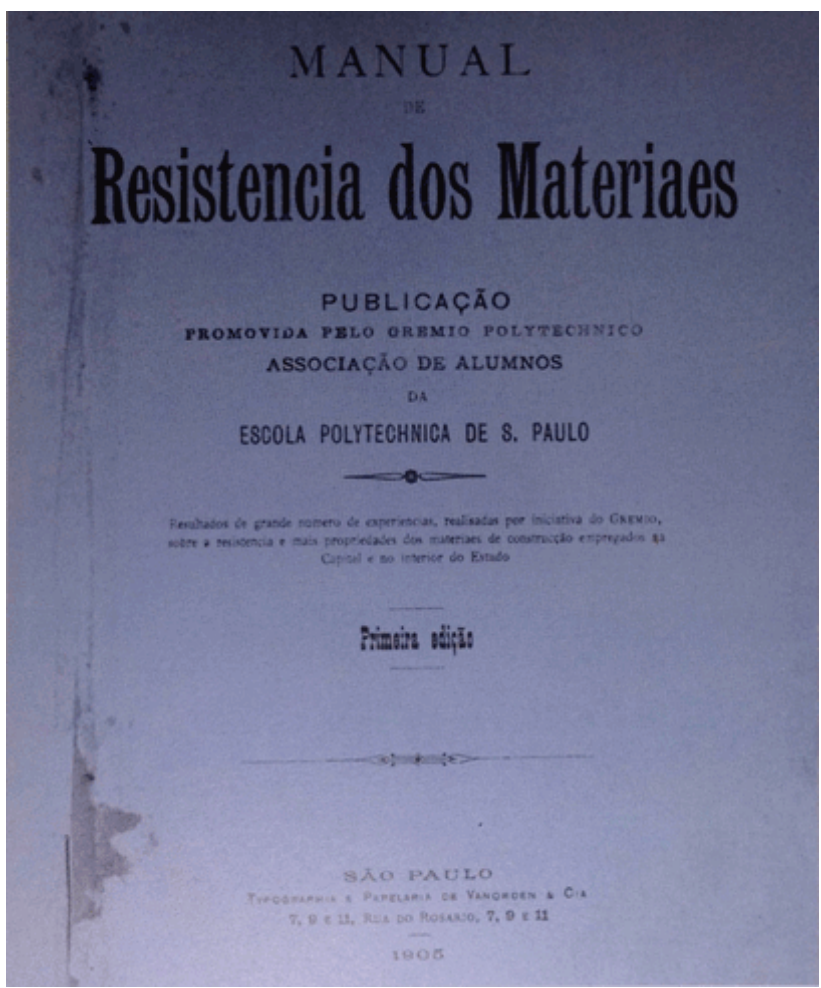

FIGURA 1

Capa do Manual de Resistência de Materiais (1905)

\section{Finalidades práticas}

A despeito de a ênfase no estabelecimento da engenharia civil e iniciativas ligadas ao problema sanitário apontar para certo pragmatismo na resolução de situações imediatas, como indicado por várias ações do governo paulista em seus primeiros anos, nota-se desde a implementação da Politécnica um expressivo debate em torno do potencial da instituição e do papel a ela atribuído em termos de projetos de futuro e inovação. ${ }^{6}$ Mesmo as controvérsias acerca da finalidade da instituição de ensino no momento de sua criação são sintomas dessas expectativas e das necessárias escolhas implicadas no projeto, desde as discussóes parlamentares em torno dos primeiros projetos de lei em 1891 e 1892, prolongadas para as polêmicas nos anos iniciais da

6 As preocupaçōes sanitárias, por exemplo, são visíveis em uma série de parâmetros técnicos e instituiçōes de apoio a seu aperfeiçoamento, como ocorre com a organização do serviço e código sanitário no estado de São Paulo entre as décadas de 1890 e 1910. Duas obras podem ser indicadas como referências importantes para aprofundar a temática sanitária em São Paulo no período, entre outras: Ribeiro (1993) e Cordeiro (2010). 
Escola em torno dos diplomas a serem oferecidos. Pode-se afirmar que os efeitos e impactos imaginados a partir da criação da Politécnica estão no centro desses debates.

Inicialmente, ainda nas discussóes dos dois projetos de lei originais, a principal polêmica situou-se em torno da suposta "vocação agrária" do estado e do país, que exigiria investimentos em uma escola de agricultura, e não de engenharia. No primeiro projeto aprovado, a dificuldade em definir uma opção parece ter levado a uma saída aparentemente conciliatória, embora a maior parte dos recursos havia sido destinada à futura Escola de Agricultura. Chama atenção ainda a definição inicial de um perfil eminentemente prático na Escola de Engenharia proposta por essa primeira lei, voltado para o que se denominou então como "indústrias":

Art. $1{ }^{\circ}$ - Fica o governo autorizado a fundar uma Escola Superior de Agricultura. [...]

Art. 6. ${ }^{\circ}$ - Fica também criada uma Escola de Engenharia, destinada a formar engenheiros práticos, construtores e condutores de máquinas, mestres de oficinas e diretores de industrias.?

A terminologia "indústria" era então associada a toda forma de atividade humana e todo emprego de tecnologia, fosse na agropecuária, no extrativismo, na coleta, na manufatura, e guardava assim relação estreita com aplicaçóes práticas do conhecimento e das ciências. ${ }^{8}$ Além disso, esse uso ampliado do termo guardava aproximaçôes com outras noções importantes no período, embora nem sempre muito precisas, como progresso, desenvolvimento ou mesmo modernização, entendida de forma bastante plural. Indústria, portanto, poderia significar desde a modernização da chamada "indústria agrícola", até os melhoramentos urbanos e a própria "indústria fabril."

Essa justificação difusa da "indústria" identificava, portanto, a necessidade de desenvolvimento e progresso defendida por variados grupos das elites nacionais, antecipada já nas argumentaçoes intensificadas às vésperas da República, principalmente em relação à instrução. Para os críticos da monarquia, republicanos liberais ou mesmo positivistas, era incontestável a importância da instrução de toda a população para se alcançar esse progresso, tal como a responsabilidade do governo na

7 Lei estadual n. 26, de 11 de maio de 1892, Autoriza o governo a fundar uma Escola Superior de Agricultura e outra de Engenharia. Disponível em: <http://www.al.sp.gov.br/repositorio/legislacao/lei/1892/lei-26-11.05.1892.html>. Acesso em: 10 ago. 2017.

8 A fundação da Sociedade Auxiliadora da Indústria Nacional, por exemplo, no Rio de Janeiro em 1820, é indicativa desta atribuição abrangente de indústria. Somente em 1904 esta sociedade defendeu abertamente a indústria fabril, quando foi transformada em Centro Industrial do Brasil (CARONE, 1977, p. 6). 
"difusão das luzes" e na promoção da instrução. Havia razoável consenso quanto a isso, mas a polêmica se colocava ao se especificar o debate em torno dos "braços para a indústria”, tema sensível para os defensores de uma escola superior de engenharia em tempos de tão flagrante necessidade de instrução básica. Ao lado da necessidade de investimento nas primeiras letras, a demanda por um ensino técnico também se mostrou controversa ao longo dos debates no parlamento paulista. Em alguns momentos, figuravam nas falas como rivais o projeto de um ensino técnico e a política de incentivo às primeiras letras, sendo aparentemente o único denominador comum conceber um ensino em bases práticas, como passou a ser defendido pela maior parte dos apoiadores da escola de engenharia.

Ainda em torno do entendimento plural sobre "indústria", ou seja, sobre o projeto de desenvolvimento a ser priorizado e incentivado, é interessante notar as soluções - poderia se dizer mesmo estratégias - encontradas para a questão do aperfeiçoamento agrícola. Somavam-se já no momento das discussões sobre a necessidade de uma escola de engenharia para São Paulo algumas decisões dos governos paulistas em favor de uma escola agrícola. Além do Instituto Agronômico em Campinas, organizado pelo governo imperial em 1887 e que passou a ser administrado pelo estado de São Paulo em 1892, no mesmo ano o governo aceitou, por meio do Decreto n. 130, a doação feita ao estado por Luiz Vicente de Souza Queiroz, filho do Barão de Limeira, de uma fazenda no município de Piracicaba com o objetivo de construir uma escola agrícola ou instituto de educação profissional ligado à lavoura. ${ }^{9}$

Ao lado da dimensão prática da escola, entende-se que a estratégia para aprovação do projeto da Politécnica e sua rápida instalação passou, nas duas primeiras décadas da instituição, pelo acolhimento a essa demanda. Ainda que a escola agrícola em Piracicaba não tenha tido imediata implementação, é interessante notar que durante quase duas décadas permaneceram sob administração do estado ao menos três instituições voltadas para finalidades agrícolas aproximando ensino e pesquisa: a escola agrícola Luiz de Queiroz; o curso de Engenheiro Agrônomo da Escola Politécnica; e o Instituto Agronômico (IAC), instituição na qual atuaram egressos da Politécnica, como Theodureto de Almeida Camargo. A simultaneidade das instituições indica ter havido possivelmente uma solução conciliatória, com a ação decisiva de Paula Souza, como diretor da Politécnica e como secretário de Agricultura, Negócios, Comércio e Obras Públicas: em 1898, ele assinou o regulamento da escola piracicabana, restringindo seu status a uma "escola prática de agricultura",

9 Decreto n. 130, de 10 de novembro de 1892. Disponível em: <http://www.al.sp.gov.br/repositorio/legislacao/decreto/1892/ decreto-130-18.11.1892.html >. Acesso em: 10 ago. 2017. 
reservando a pesquisa de cultivares para aperfeiçoamento da agricultura ao IAC e a formação de engenheiros agrônomos à Politécnica. ${ }^{10}$

A primeira lei de criação de uma instituição de ensino de engenharia, portanto, a Lei n. 26 de maio 1892 estabelecendo uma escola superior de agricultura e uma escola prática de engenharia, foi incorporada a outros projetos sem ter tido sua proposta realizada, de fato. E situação similar ocorreu com a segunda instituição criada cerca de três meses depois, em agosto de 1892.

Art. $2^{\circ}$ - O "Instituto Politécnico de S. Paulo" compor-se-á de uma escola preparatória e de cursos especiais de engenharia civil, engenharia mecânica, arquitetura, quimica aplicada ás industrias, agricultura e ciências matemáticas e naturais. ${ }^{11}$

Novamente o debate recaiu sobre a necessidade de uma escola prática diante da proposta do Instituto, cujo perfil pareceu aos legisladores estar mais próximo duma instituição de ensino superior voltada para estudos teóricos, sobretudo pela presença de ciências matemáticas e naturais. Aparentemente, a existência de diplomação em ciências matemáticas, naturais e físicas na Politécnica do Rio de Janeiro, ao lado da abertura dessa nova lei para a existência de uma escola preparatória, possibilitou aos legisladores mobilizar referências de instituições já conhecidas, cuja estrutura e funcionamento pudessem servir de apoio a uma terceira proposta, capaz de conciliar expectativas e possibilidades exequíveis para efetivar-se. A solução que viabilizou a Escola Politécnica, depois de conjugar-se com o ensino e a pesquisa agrícolas, estabeleceu claramente os distintos níveis do ensino que pretendia desenvolver: uma escola superior, mas de ciências aplicadas, contemplando a expectativa por um ensino prático; curso anexo de artes mecânicas, para oferecer resposta mais rápida aos anseios pela formação "de braços"; curso preparatório, adequado à necessidade de formação; e iniciação teórica para os cursos superiores. A Lei n. 191, aprovada uma semana após a anterior, aprova o primeiro regulamento da Escola, que foi ajustado já no ano seguinte: "Art. 1. o- Fica criada na cidade de S. Paulo uma escola superior de matemáticas e ciências aplicadas ás artes e industrias, que se denominará 'Escola Politécnica de S. Paulo”. No regulamento de 1894, primeiro ano de funcionamento efetivo da Escola:

10 Decreto n. 611, de 9 de novembro de 1898. Dá regulamento para a Escola Agrícola Prática de Piracicaba. Disponível em: <http://www.al.sp.gov.br/repositorio/legislacao/decreto/1898/decreto-611-09.11.1898.html>. Acesso em: 10 ago. 2017. Pouco mais de uma década depois, uma reforma no regulamento da Escola Politécnica transferiu o curso de engenheiro agrônomo para Piracicaba, reestruturando a escola por meio da Lei n. 1356, de 19 de dezembro de 1912. Reorganiza a Escola Agrícola "Luiz de Queiroz", de Piracicaba

11 Lei n. 64, de 17 de agosto de 1892, Cria nesta capital o Instituto Politécnico. Disponível em: <https://www.al.sp.gov.br/repositorio/legislacao/lei/1892/lei-64-17.08.1892.html>. Acesso em: 7 jun. 2017. 
Artigo 1. ${ }^{\circ}$ A Escola Politécnica de S. Paulo se comporá de dois cursos fundamentais $e$ de diversos cursos especiais.

Artigo 2. ${ }^{\circ}$ Os cursos fundamentais serão constituidos:

a) Pelo curso preliminar.

b) Pelo curso geral.

Artigo 3. - Os cursos especiais serão os seguintes:

I) Curso de engenheiros civis.

II) Curso de engenheiros arquitetos.

III) Curso de engenheiros industriais.

IV) Curso de engenheiros agrônomos.

V) Curso de mecânicos.

VI) Curso de maquinista.

S único. - Sem constituirem cursos especiais, haverá também os seguintes cursos, que serão constituidos pelas matérias dos cursos fundamentais.

a) De contadores.

b) De agrimensores.

c) De engenheiros geógrafos ${ }^{12}$.

Tornou-se essa, por fim, a organização inicial da Escola Politécnica, sendo acrescida do curso de engenheiro eletrotécnico em 1907, além da supressão do curso de engenheiro agrônomo, mencionada, e outras mudanças pontuais. Nesse percurso para viabilizar um projeto que mesclasse propostas e possibilidades efetivas, sem fraturar presumíveis alianças em torno de projetos mais abrangentes para o desenvolvimento do estado, aparentemente configurou-se o perfil teórico-prático, voltado para um conhecimento aplicado, reiterado numerosas vezes na trajetória da própria Politécnica. Possivelmente é esse perfil que orientou o discurso de Paula Souza diante da primeira turma de formandos da escola, em 1899:

Encontramos facilmente quem discorra sobre os mais variados assuntos, quem mostre a mais invejável erudição; todavia, é bem raro encontrar quem possa executar mesmo as mais simples coisas. [...] Ora, é claro que se precisava reagir a este estado de coisas: e esta escola é a expressão desta reação. (ESCOLA POLYTECHNICA DE SÃO PAULO, 1900)

12 Decreto n. 270A, de 20 de novembro de 1894. Disponível em: <https://www.al.sp.gov.br/repositorio/legislacao/decreto/1894/ decreto-270A-20.11.1894.html>. Acesso em: 7 jun. 2017. 


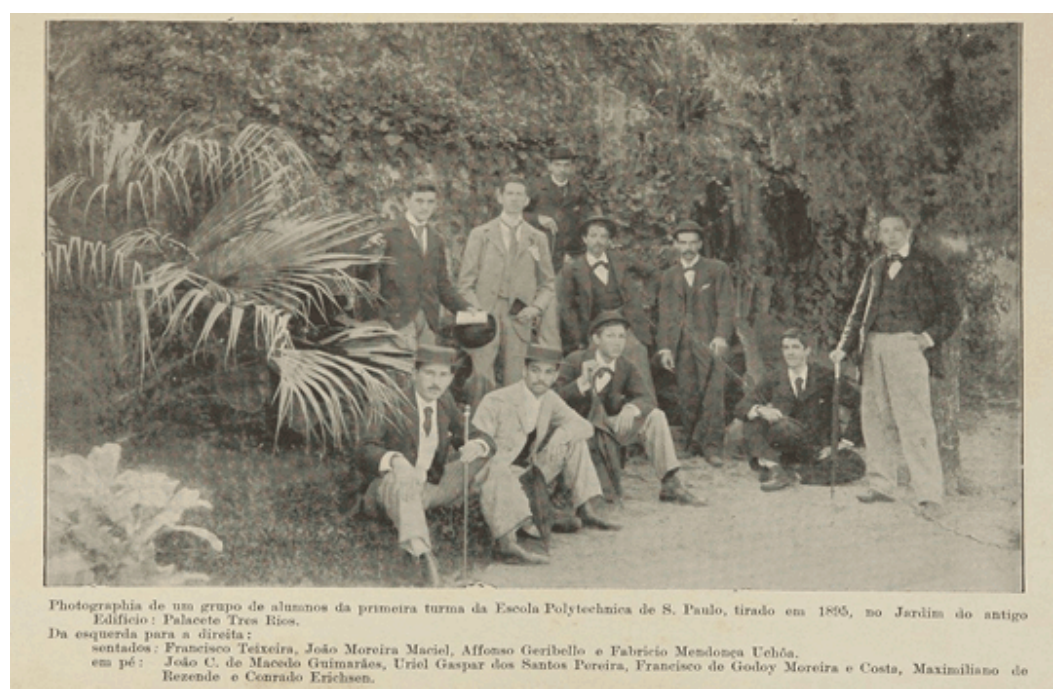

FIGURA 2

Alunos da Escola Politécnica nos primeiros anos da instituição.

Annuário da Escola Politécnica para o ano de 1933.

\section{Inovação e vocabulário alinhados}

Embora seja possível apontar ações voltadas para inovação em diferentes momentos da história da instituição a partir da consolidação desse perfil, como os exemplos dos laboratórios acima deixam entrever, justifica-se a seleção de dois documentos textuais como indícios de tais aspectos pelo papel a eles atribuído no desenrolar dos conhecimentos. Todos se apresentam como referenciais, como balizadores de uma nova possibilidade, ao mesmo tempo exigente de novos saberes e novas ferramentas. ${ }^{13} \mathrm{O}$ primeiro é a publicação na Revista Politécnica, de responsabilidade do Grêmio Politécnico, de um "Vocabulário Técnico" em vários números consecutivos, como um esforço coletivo de definir, de precisar o vocabulário empregado em livros técnicos, sobretudo estrangeiros, a fim de superar os inconvenientes da dificuldade de entendimento. Assumiu o vocabulário sobre construções civis o professor então recém-contratado, egresso do curso de engenheiro arquiteto, Alexandre Albuquerque (1860-1940). ${ }^{14}$

13 Há diferentes publicaçōes, sobretudo de caráter comemorativo, que abordam de diversas maneiras as iniciativas da Politécnica e podem com segurança apresentar inovaçōes mais ligadas a transformações instrumentalizadas pela instituição. Entre elas, destacam-se o trabalho de Loschiavo dos Santos (1985), com extenso levantamento sobre a organização de cada setor da Politécnica, e o estudo de Motoyama (2004), que, em parceria com Marilda Nagamini, elaborou uma abrangente análise de cada campo de atuaçăo dos politécnicos a partir da Escola.

14 Está reproduzido aqui apenas o primeiro número, publicado na Revista Politécnica n. 55, de 1918, abarcando a letra A. Posteriormente, em 1940, todos os vocábulos foram também reunidos e publicados na obra póstuma de Albuquerque, Construcçōes Civis. 
O segundo léxico foi publicado por Afonso Teixeira d'Escragnole Taunay (1876-1958), engenheiro civil formado na Politécnica do Rio de Janeiro em 1900, e dedicou-se posteriormente aos estudos de historiografia, destacando-se com pesquisas sobre o bandeirismo paulista e o período colonial brasileiro. Como engenheiro foi professor de química na Escola Politécnica e posteriormente na Faculdade de Filosofia, Letras e Ciências Humanas da USP. O léxico reproduzido aqui reúne quantidade impressionante de verbetes, mais de cinco mil, que, segundo justifica, constituem lacuna importante nos dicionários da língua portuguesa em questôes técnicas e científicas. Foi publicado no Anuário da Escola Politécnica para o ano de 1909, junto a outras contribuições dos docentes da escola, conforme se acompanha no sumário, reproduzido como exemplo do perfil das produções anualmente publicadas pela Politécnica. ${ }^{15}$

\section{VOCABULARIO TECHNICO}

\footnotetext{
Uma das grandes inconveníencias que nos traz o estudo nos livros escriptos em linguas estrangeiras é a difficuldade em que nos achamos quando devemos discutir assumptos referentes á profissão do engenheiro. so do engenheiro? Não: outro tanto se verifica nas outras profissóes. Os medicos e advogados, como os engenheiros, formam as suas bibliothecas de livros francezes, inglezes, italianos, etc. A nossa literatura scientifica é pauperrima e, emquanto nâo se constituir e divulgar o nosso vocabulario scientifico, nåo será possivel o seu desenvolvimento.

O assumpto começa a interessar a classe dos engenheiros, tanto que, o Club de Engenharia do Rio de Janeiro, projecta, para o centenario da nossa Independencia, a publicação de um vocabulario technico brasileiro.

A Revista Polytechnica, no intutito de contribuir, com ums parcella modeeta, para ume obre tão meritoria, inlcla, hoje, a publicação de um Vocabulario Technico, para cujo exito solicita o apoio da classe dos engenheiros.

A commissão da "Revista" entregou a direcçăo deste serviço ao engenheiro Octavio Ferraz Sampaio, m. d. Director do Gabinete de Electrotechnica da Escola e conta com o apoio decidido dos corpos docente e discente. Solicita, a mesma commissão, aos que se interessarem pelo assumpto, que enviem, á redacção, listas dos termos technicos que encontrarem durante os seue estudos, tanto quanto possivel, com a traducção para o vernaculo e a respectiva definiçâo; tal qual publicamos, a seguir, a parte da letra A, referente á construç̧ão eivil. Este trabalho é a contribuiçáo do nosso illustrado collaborador, engenheiro Alexandre de Albuquerque, lente-substituto da cadeira de Construç̧óes Civis.
}

15 Os anuários foram publicados em três séries: de 1900 a 1912, de 1932 a 1938 e de 1946 a 1947. 
APLosiB, Aprumo. Perpendicu-
larmente levantado. APorifge, Apophyse. Annel
que elrcunda. fuste da columna que eircunda 0 fuste da columna
logo acima da base, ou perto do capitel.
APOTHECA, Apotheen, Logar, ardavam comesti. vels, o princlpalmente vinhos para envelhecer, na: 2 - primeira camada de plinfusiamento das pedras que cons. tituem uma alvenaria. Cobertura APPTNTIS, A1pendre. Cobertura
nallente, do uma 80 agua, sustentada por columnas, ou pliastras, de
um lado e encostado, pelo outro, em uma parede na APPUI, Apoio. Templo desprovido de columnas. AQUARELLE, Aquarella AQUEDUC, Aquedacto. natos imitando folhas, flores, frue-
tos e fitas interlacadas, a maneira arabe. ARsen, Espalmar, Respaldar.

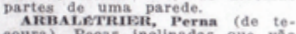
soura). Pecas inelinadas que vâ do frechal a cumlinira
ARBLETHERE. Bésteira.

Alt, Areo, Botaréo. Construccho exterior, ter,
minada em arco, caracteristica da rchltectura oglva

ARCATURE, Areatura, Arcarle fingida que orna differentes partes

manjica),
Altovid, Areo de desearga.

AltchE, Areo de ponte,

phia. Descripcaso dos monumentos

Antigosicologin, Areheologia, Es. tudo da antiguidade, no ponto de
vinta da arte, dos costumes usos

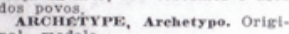$$
\text { ARCHTECTE, Arehiteete. }
$$

ARCHTECTUike, Arehiteetura.
ARCHIVOLTE, Arehivolta. Mol. dura que Euarnece o extradorso
do um areo servindo a sua decoraAirporse, Andosia.

Ane, Areo. cem metros quadrados, phitheatro Ande combatiam os gla. paraça das madelras com a plaArAussques, Arabeseos. Or. Fazer plano como a paima da má.
Por so mesmo nivel as diversas

AReOSTYLE, Areostylo, Entre os antigos, edificios com colum tras Modernamente, systema estấo collocadas a oito modulos, as vezes, dez modulos. saltenter formado pelo encontro do duas faces de um corpo solido.
Nos telhados as arestas tomam o

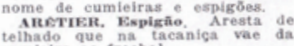
umieira ao frechal. metal fixa aos. Arganel, Argola de vindo para amarragáo das embar. ARgenture, Prateadura.

ARMATURE, Arni tura, connexăo, travação das par A entre si.s. Armillas. Membro de arehitectura des basies das co-
lumnas: dols, tres ou quatro anARMome, Armario. ARMOMmEs, Armas, Termo do familias nobres om seus escudo para se distinguirem umas das inguir cldades ou povos.
Amovint (Queue d') Anderinhn. (Rabo de). Systema de sambladu. ARPENT, Geira, Medida agraria trancestistake, Topographin, meAiçaio de terras. arco. Ahever, Arquear. Dar tormi de arco. los, ou pedras, que ficam sallen-
tes na extremlade de uma parede que sera posteriormente construiARSENAL, Arsenal.

AnTichite, Aleaehofra, Lavor imitando alcachofras.
AITisav, Artifice.

IRTISTE, Artista.

ASCENSEDR, Elevador. Betume escuro, lustroso e friavel, encon-
trado prineipalmente no higo As. phaltite. ASSECHEMENT, Seece, Enxugo ASsEMminge, Sambladura. Jun-
tura de uma peca de madelra con outra,
Assiere, Assentumente. Assisk, Fiada. Carrelra horizontal de tijolog, ou pedras. A al. dois leitos successivos. Astrugate, Astrágate, Moldu-

$$
-43-
$$

ra composta de um toro e de um fidate, que separa o capitel do fuste ATHENEE, Athêneu. Templo de Minerva: templo onde se reunlam os sabios e os poetas para lerem de bellas-artes. ATLANTE, Atlante. Figura, ou
nela figura de homem que serve ATrE, Lareira. Pedra do lar,
sobre que se accende lume pelo inverno.

ATricurge, Atticongo. Obra

atticurga. Attico. Coroamento de ATTRQVE, Attico. Coroamento de
dificlo. Andar secundario que co edificio. Andar secundar
roa um grande edificio. ATrrindTs, Attributos. Symbo-
los, signaos distinctivos: attribuAs da architectura Ausar; logar Anderke. Casa de

guem por carldade.

AUBiER, Alburno, Snmo. A parte a casca co cerne. AvGE, Estaneia. Taboa em que
pedreiros têm a argamassa, de AULNE, AUNE, Amieiro. AUMONERE, Amieiro.

ralmente uma dependencla dos anAUREOLE, Aureola, Resplandor. irculo luminoso ao redor de uma vindade. Altur. Mesa destinada AVTEL, Altar. Mesa destinada
aos sacrificios. Especip de mesa on-
de ge diz a missa nos templos caAUVENT, Tejadiho. Pequeno telliado Inelinado. collocado acima val-as da chuva.
AVAvT-cavin, Antechoro. Sa-
la que antecede ao choro, e da serventia para elle. AVANT-Corrs. Corpo saliente. massiço de alvenaria fazendo saAVANT-PRoJET, Anteprojecto. ovos antigos, a parte do theatro nos theatros modernos, 6 a a parte as scena que val do grande arco AVANT-TOrT; Beiral. Tecto fazendo sallencla sobre a fachada.
AVENTURINE, Aventurina. PeAVEUGLE (Fenetre) Fingldn (janella)
AZURo, Axulejo.
AzUR, Axul. (Continua

\section{FIGURA 3}

Vocabulário Técnico, parte 1. Revista Politécnica, n.55, 1918 


\section{ANNUARIO}

DA

\section{Escola PolyTechilca}

DE

S. $P \& U \perp 0$

PARA O ANNO DE 1909

9. ANNO

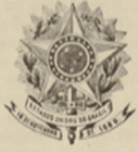

SẢO PAULO

TYPOGRAPHIA BRAZIL DE ROTHSCHILD A CO

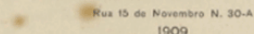

\section{INDICE} Commissão de Redaç̣ão:
Prefacio

Pags

Dr. Affonso d'E. Taunay:

\section{1.a Parte}

Lexico de termos technicos e scientificos ainda não apo tados nos diccionarios da lingua portuguera

Dr. Antonio de Cerqueira Cesar:

Generalisação da formula do binomio para o caso de um expoente qualquer.

Drs. R. Hottinger e 0. Pitsch:

Trabalhos e experiencias effectuados em o Laboratorio de Zootechnia:

a) Influencias da alimentação, elevagem e tratamento sobre o desenvolvimento das fórmas e aptidōes demonstrada no gado Schwytz, por O. PrTscil

Medificacio de methode de Gram, por R. Hornvers

Experiencias compativas sobre a modificacie do Experiencias comparativas sobre a modíicação do Preparo e emprego da gelatina na bacteriologia, por R. Homrivezr. Apparelho simples para a dosagem de gaz produzido por microbios, por R. Hotriverk . zido por microbios, por $\mathrm{R}$. HotTisakz
Sobre a grandeza dos erros nas modificações biologicas, por R. HOTtINGER.

O canto do gallo á noite é um exemplo de propriedade adquirida por hereditariedade, por R. HoTTINGEK . . . . . . . .

h) Projecto para a debellação das doenças contagiosas, por R. Hortisoek.

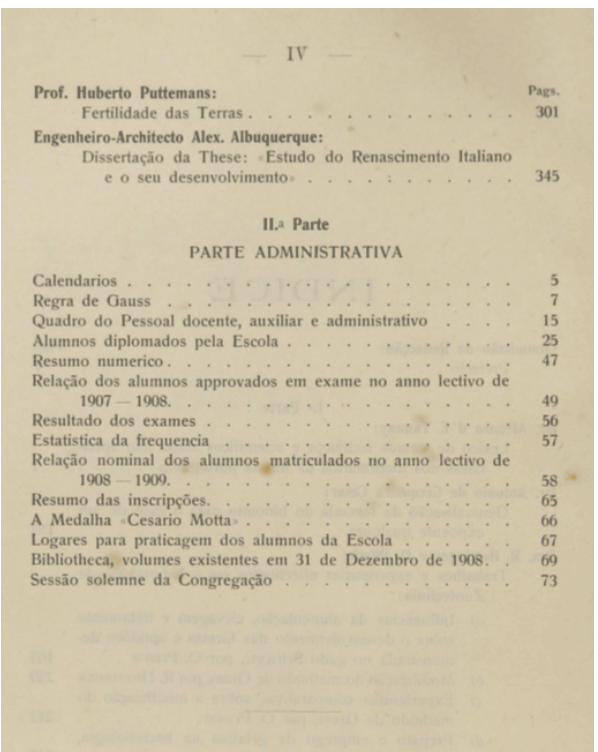




\section{LEXICO}

DE

\section{Zermos technicos e scientificos}

ainda näo apontados nos diccionarios $\partial \mathrm{a}$ lingua portugueza

ORGANISADO

rok

Affonso d'E. Taunay

\section{Advertencia}

Peccam os melhores diccionarios da nossa lingua pela grande deficiencia do vocabulario technico scientifico. 0 de Caldas Aulete, tão notavel pela excellencia de definições e propriedade exemplificação que o collocam em nivel eminentemente superior ao dos demais lexicos, apresenta enorme quantidade de lacunas, a ponto de não ser possivel tel-o alguem como unico diccionario de consulta. sob pena de se ver a cada passo embaraçado com a falta de informações, frequentemente triviaes até.

Essas lacunas numerosissimas quanto á linguagem vulgar, ainda mais avultam quando se trata do vocabulario seientifico, embora Aulete sobremaneira distanciasse, nesse particular, aos antigos e tão restrictos, Moraes, Constancio e Vieira, com as suas ingenuas definiçôes, dignas, por vezes, do famoso Bacellar.

0 Snr. Candido de Figueiredo apontou trinta mil palavras ainda não catalogadas, figurando nesse volumoso contingente grande copia de termos scientificos, uma boa terça parte talvez.

A Encyclopedia Portugueza, de Maximiliano de Lemos, ajuntou a esses trinta milheiros outros muitos.

Ainda assim para os pesquizadores humildes ha que respigar nessa seara tào cuidadosamente recolhida pelos grandes lexicographos. Foi o que o despretencioso confeccionador deste pequeno supplemento aos grandes diccionarios da lingua pode fazer, aliás em lapso muito restricto e nas folgas que the deixam arduas obrigações diarias, pois muitissimo resta averbar nesse enorme inventario de termos technicos e scientificos que continuamente avolumam o espantoso progresso das sciencias, o desenvolvimento e aperfeiçoamento das industrias, a serie ininterrupta das grandes invenções e descobertas e a consequente creaçâo de novas technologias e amplificação, em grandes proporções, das já existentes. 

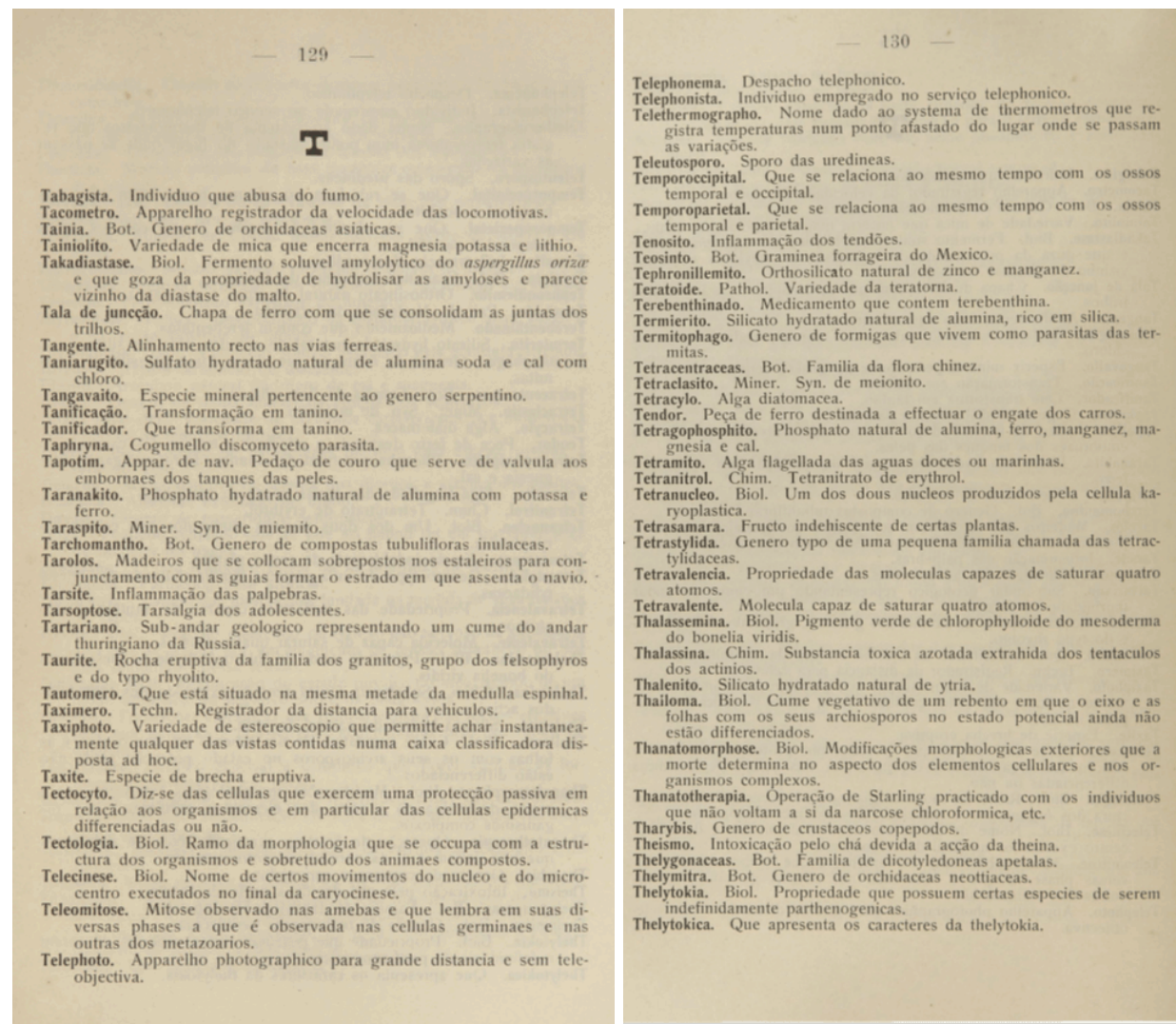

FIGURA 4

Léxico de termos técnicos e científicos, Anuário da Escola Politécnica, 1909 (trechos)

A partir dos elementos aqui discutidos e apresentados sobre as primeiras décadas da Politécnica paulista, buscou-se discutir os significados da fundação dessa instituição em suas distintas aproximações com projetos em pauta na sociedade e a então crescente importância da técnica e da ciência, não apenas para os engenheiros que buscavam legitimar seu espaço de ação no período. $\mathrm{O}$ estabelecimento dessa instituição, declaradamente voltada para valorizar a prática em sua relação com dimensões teóricas do conhecimento, é apoiado por projetos colocados em pauta por setores das elites nacionais naquele período. Não se pode compreendê-lo como iniciativa individual ou única possibilidade existente, mas como uma das opções diante das dinâmicas social, culturais e políticas do período - situação visível nas polêmicas em torno da aprovação do projeto inicial pelo Legislativo paulista, analisadas nestes apontamentos. Outro indício da inserção da Politécnica nos debates 
em pauta no período pode ser notado no próprio processo de implementação da instituição, nas primeiras reformulações de seus cursos e programas, bem como nas escolhas realizadas para constituição de sua biblioteca de referências. Os registros dos anuários e dos relatórios periódicos dos diretores da Escola permitem matizar a ênfase prática e teórica, bem como os distintos diálogos e posicionamentos que se buscou sublinhar em sua formação.

\section{Referências bibliográficas}

ASSOCIAÇÃO BRASILEIRA DE NORMAS TÉCNICAS. História da normalização brasileira. Rio de Janeiro: ABNT, 2011.

ASSOCIAÇÃO DOS ANTIGOS ALUNOS DA ESCOLA POLITÉCNICA. Escola Politécnica: 100 anos. Pesquisa, iconografia e redação de José Luiz Aidar, Roney Cytrynowicz e Judith Zuquim. Rio de Janeiro: Expressão e Cultura, 1993.

BONTEMPI JR., Bruno. Escola politécnica de São Paulo: produção da memória e da identidade social dos engenheiros paulistas. História da Educação, Santa Maria, v. 19, n. 46, p. 223-242, maio/ago. 2015. Disponível em: <http://www.scielo.br/scielo.php?script=sci_ arttext\&pid=S2236-34592015000200223\&lng=pt\&nrm=iso >. Acesso em: 3 dez. 2017.

CAMPOS, Cristina de. Ferrovias e saneamento em São Paulo. O engenheiro Antonio Francisco de Paula Souza e a construção da rede de infraestrutura territorial e urbana paulista, 1870-1893. Campinas: Pontes ed., 2010.

CARONE, Edgard, O pensamento industrial no Brasil (1880-1945). Rio de Janeiro, São Paulo: Difel, 1977 (Coleção Corpo e Alma do Brasil).

CERASOLI, Josianne Francia. A grande cruzada: os engenheiros e as engenharias de poder na Primeira República. Dissertação (Mestrado em História Social) - IFCH-Unicamp, Campinas, 1998.

. Títulos e braços: ensino politécnico e projetos políticos no Brasil. Revista Comunicaçôes, v. 14, n. 2, 2007. Disponível em: <http://dx.doi.org/10.15600/2238-121X/ comunicacoes.v14n2p87-99>. Acesso em: 2 set. 2017.

CORDEIRO, Simone Lucena (Org.). Os cortiços de Santa Ifigênia: sanitarismo e urbanização (1893). São Paulo: Arquivo Público do Estado de São Paulo, Imprensa Oficial, 2010.

ESCOLA POLYTECHNICA DE SÃO PAULO. Annuário da Escola Polytechnica de São Paulo para o anno de 1900. São Paulo: Typographia do Diario Official, 1900. 
Relatório do ano de 1908 apresentado ao Exmo. Dr. Dr. Carlos Augusto Pereira Guimarães, d.d. Secretário do Estado dos Negócios do Interior pelo diretor engenheiro civil Antonio Francisco de Paula Souza. 1908. Disponível em: <http://memoria.poli.usp.br/han dle/123456789/176?discover?rpp=10\&etal=0\&query=regulamentos\#page $/ 31 /$ mode $/ 1$ up $>$. Acesso em: 2 jun. 2017.

ESCOSTEGUY, Jorge (Ed.). Escola Politécnica: cem anos de tecnologia brasileira. Colaboração de José Luiz Vitú do Carmo e Wagner Barreira. São Paulo: Grifo Projetos Históricos e Editoriais, 1994.

GITAHY, Maria Lucia Caira. Adaptando e inovando: o Laboratório de Ensaios de Materiais da Escola Politécnica e a tecnologia do concreto em São Paulo. História, Ciências, Saúde-Manguinhos, Rio de Janeiro, v. 7, n. 3, p. 675-690, fev. 2001. Disponível em: <http:// www.scielo.br/scielo.php?script=sci_arttext\&pid=S0104-59702001000600006\&lng=pt\&n rm=iso>. Acesso em: 3 set. 2017.

GITAHY, Maria Lucia Caira; PEREIRA, Paulo César Xavier (Org.). O complexo industrial da construção e a habitação econômica moderna (1930-1964). São Carlos: Rima, 2002.

MOTOYAMA, Shozo (Org.). Escola Politécnica, 110 anos construindo o futuro. São Paulo: Edusp, 2004.

(Org.). Tecnologia e industrialização no Brasil: uma perspectiva histórica. São Paulo: Ed. da Unesp e Ceeteps, 1994.

PUJOL JR., Hippolyto Gustavo. O manual de resistência de materiais. Revista Polytechnica - orgam do Gremio Polytechnico, São Paulo, v. II, 1905.

SANTOS, Maria Cecília Loschiavo dos. Escola Politécnica da Universidade de São Paulo: 1894-1984. São Paulo: Escola Politécnica e Fundação para o Desenvolvimento Técnico da Engenharia, 1985.

SÃO PAUlO (ESTADO). Annaes da Sessões Ordinarias da Camara dos Deputados. 1891, 1892, 1893, 1912.

RIBEIRO, Maria Alice Rosa. História sem fim... Inventário da saúde pública, São Paulo 1880-1930. São Paulo: Ed. Unesp, 1993

SOUZA, Ana Cláudia Ribeiro de. Escola Politécnica e suas múltiplas relaçôes com a cidade de São Paulo, 1893-1933. Tese (Doutorado em História) - PUC-SP, São Paulo, 2006.

STENGERS, Isabelle. Quem tem medo da ciência? Ciência e poderes. Trad. Eloisa de Araújo Ribeiro. São Paulo: Siciliano, 1990. 
